\title{
Incidence and risk factors of polycystic ovary syndrome among women in reproductive age group attending a tertiary health care hospital in Western Maharashtra
}

\author{
Khushboo S. Shinde ${ }^{1 *}$, Sunil S. Patil ${ }^{2}$
}

\begin{abstract}
${ }^{1}$ Student, Byramjee Jeejeebhoy Government Medical College and Sassoon General Hospital, Pune, Maharashtra, India ${ }^{2}$ Department of Obstetrics and Gynecology, Byramjee Jeejeebhoy Government Medical College and Sassoon General Hospital, Pune, Maharashtra, India
\end{abstract}

Received: 10 May 2019

Accepted: 11 June 2019

\section{*Correspondence:}

Dr. Khushboo S. Shinde,

E-mail: 96kshinde@gmail.com

Copyright: () the author(s), publisher and licensee Medip Academy. This is an open-access article distributed under the terms of the Creative Commons Attribution Non-Commercial License, which permits unrestricted non-commercial use, distribution, and reproduction in any medium, provided the original work is properly cited.

\begin{abstract}
Background: Polycystic Ovary Syndrome (PCOS) is an endocrine disorder affecting women of reproductive age group. Though its incidence is markedly increasing, the awareness is still low; as a result it remains undiagnosed. Aim of this study was to find the incidence and risk factors of PCOS among women in reproductive age group, so as to encourage young women to seek timely treatment and prevent its long term complications.

Methods: A study was conducted over a period of 1 year amongst 100 women attending the Gynecology OPD using a paper based questionnaire. General examination and the required laboratory tests were done to confirm the diagnosis.

Results: It was found that the incidence of PCOS among the study population was $21 \%$. Risk factors include lack of physical activity, irregular menstrual cycle, body mass index more than 25, and Waist-hip ratio above 0.86 .

Conclusions: It is seen that there is a need to educate women at an early stage to prevent the development of this syndrome and its early detection by them. This will facilitate the health professionals to start the treatment at a stage where the complications have not yet set in.
\end{abstract}

Keywords: Anovulation, Body mass index, Hyperandrogenism, Infertility, PCOS, Waist-hip ratio

\section{INTRODUCTION}

In 1935, Irving F. Stein and Michael L. Leventhal described a symptom complex associated with anovulation - Polycystic Ovary Syndrome. PCOS is an endocrine disorder among women of reproductive age group characterized by hyperandrogenism, increased Luteinizing Hormone: Follicle Stimulating Hormone ratio, impaired glucose tolerance, insulin resistance. Other symptoms include menstrual irregularities, pelvic pain, acne, anxiety, weight gain, hirsutism, alopecia.
Immaturity of hypothalamic-pituitary-ovarian axis in girls causes anovulation due to suboptimal FSH and LH production causing irregular menses in the early years of menarche. This state corrects on its own after few years resulting into regular ovulatory cycles as the H-P-O axis matures. In some young girls however anovulation persists and continues as chronic anovulation. The resulting hyperestrogenism, leads to hyperandrogenism. ${ }^{1}$

The World Health Organization estimates that PCOS has affected 116 million women worldwide as of 2010 (3.4\% 
of the population). ${ }^{2}$ The prevalence of PCOS depends on the choice of diagnostic criteria. Most prevalence studies in India and recently a few studies among adolescents in schools report prevalence of PCOS as $9.13 \%$ to $36 \% .^{3}$ Apart from these problems, PCOS has serious complications like infertility also. Women with PCOS are at an increased risk of developing type 2 Diabetes, dyslipidemia, heart diseases. Also, a Danish cohort study conducted in 2015 published that the prevalence of endometrial carcinoma increases fourfold in PCOS affected women. ${ }^{4}$

Even today there is a general lack of awareness regarding the condition in India and it often remains undetected for years. Despite all the knowledge, there is no cure for PCOS yet. The mainstay of treatment is regular exercise, weight control and oral contraceptive pills. Therefore to reduce the incidence of PCOS, most appropriate strategy would be to prevent its development which can be achieved only if majority of the women are aware of the disease and its future complications.

With this background it seems that there is a need to understand the various factors involved in the development of PCOS, so that efforts can be made to control or minimize the risk factors and create awareness for prevention and encourage them to seek timely treatment and prevent its long term complications.

The objective of this study was to assess the incidence of PCOS among women in the sample population. To assess the risk factors of PCOS. To create awareness about PCOS and its consequences amongst them.

\section{METHODS}

It was observational and cross-sectional study. Gynecology out patient department (OPD) of a tertiary health care Hospital.

Study period of this study was 1 year (1 February 2018 -1 February 2019).

\section{Inclusion criteria}

- All women in the reproductive age group (15-49 years) attending the Gynecology OPD for gynecological complaints

- Females in the reproductive age group accompanying the patients

- Women willing to participate.

\section{Exclusion criteria}

- Menopausal women

- Patients with gynecological malignancies such as ovarian cancer, endometrial cancer, cervical cancer etc.

- Patients with androgen secreting adrenal tumors

- Pregnant females
- Patients unwilling to participate in the study.

An observational study was conducted amongst the women in the reproductive age group visiting the Gynecology out patient department (OPD) of a tertiary health care Hospital. The sample size was calculated considering the average prevalence as 20 i.e. $\mathrm{p}=20 \%$ (based on previous researches), confidence level of $95 \%$ with the margin of error as $8 \%$ and was found to be 100 . A written and informed consent was obtained from all the participants. A confidential interview using a paper based questionnaire was conducted among the participants. The questionnaire comprised of questions which collected mandatory information regarding:

- Socio-demographic characteristics of the respondent such as the age, education, marital status, socioeconomic class etcetera

- Menstrual history (age at menarche, past menstrual cycle)

- $\quad$ Body mass index (BMI)

- Waist hip ratio

- Physical activity

- Past, personal and family history

- Awareness about PCOS and its complications.

\section{Statistical analysis}

The participants underwent a general examination where parameters like their height, weight, pulse, blood pressure, presence/absence of hirsutism etc. were checked. Women with positive clinical features and findings were then subjected to laboratory investigations like fasting blood sugar level, FSH and LH levels, thyroid stimulating hormone, Free T3 and T4 levels and ultrasonography to confirm the diagnosis. Final diagnosis was made using Rotterdam criteria (2003). The data was analysed by EPI INFO 7 version. Significance of the test was decided at $p$-value $<0.05$. Odds ratio and $95 \%$ confidence interval were calculated to see the risk.

\section{RESULTS}

A total of 100 women participated in this study. From the study it was found that the incidence of Poly Cystic Ovarian Syndrome (PCOS) among the study population was $21 \%$ (Figure 1).

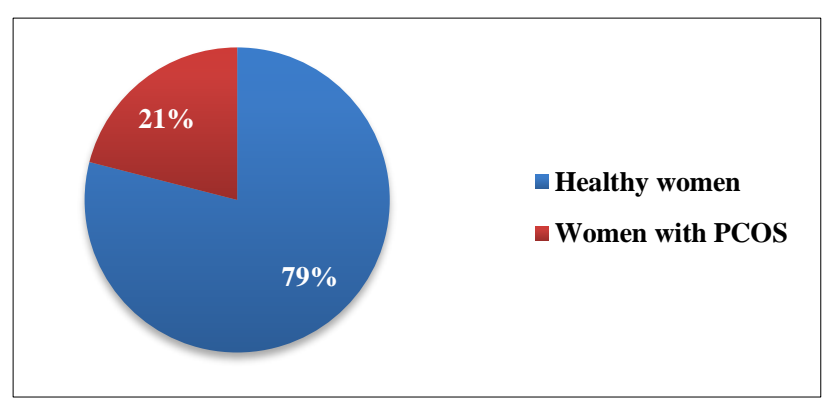

Figure 1: Incidence of PCOS. 
Table 1: Association of socio-demographic profile with PCOS.

\begin{tabular}{|c|c|c|c|c|c|}
\hline Characteristic & $\begin{array}{l}\text { Total } \\
\mathrm{n}=\mathbf{1 0 0}\end{array}$ & $\begin{array}{l}\text { Healthy }(\%) \\
n=79\end{array}$ & $\begin{array}{l}\operatorname{PCOS}(\%) \\
n=21\end{array}$ & $\begin{array}{l}\text { Odds ratio ( } 95 \% \\
\text { confidence interval) }\end{array}$ & $\begin{array}{l}\text { Chi square test/ } \\
\text { p Value }\end{array}$ \\
\hline \multicolumn{6}{|l|}{ Age (years) } \\
\hline$\leq 24$ & 61 & $45(73.77 \%)$ & $16(26.22 \%)$ & \multirow{2}{*}{$0.41(0.12-1.21)$} & 2.57 \\
\hline$\geq 25$ & 39 & $34(87.18 \%)$ & $5(12.82 \%)$ & & $\mathrm{p}=0.10$ \\
\hline \multicolumn{6}{|l|}{ Marital status } \\
\hline Unmarried & 50 & $38(76 \%)$ & $12(24 \%)$ & \multirow{2}{*}{$0.69(0.25-1.86)$} & 0.54 \\
\hline Married & 50 & $41(82 \%)$ & $9(18 \%)$ & & $\mathrm{p}=0.46$ \\
\hline \multicolumn{6}{|l|}{ Education } \\
\hline $\begin{array}{l}\text { <primary ( } 7 \text { standard and } \\
\text { below) }\end{array}$ & 16 & $15(93.75)$ & $1(6.25 \%)$ & \multirow{2}{*}{$4.63(0.75-104)$} & 2.49 \\
\hline $\begin{array}{l}\text { Zhigh school (10 standard } \\
\text { and above) }\end{array}$ & 84 & $64(76.19 \%)$ & $20(23.81 \%)$ & & $\mathrm{P}=0.11$ \\
\hline \multicolumn{6}{|l|}{ Socioeconomic class* } \\
\hline Upper & 31 & $20(64.51 \%)$ & $11(35.48 \%)$ & \multirow{2}{*}{$0.31(0.11-0.85)$} & 5.68 \\
\hline Lower & 69 & $59(85.51 \%)$ & $10(14.49 \%)$ & & $\mathrm{P}=0.01$ \\
\hline
\end{tabular}

p value < 0.05 is considered significant; *Socio-economic class was calculated according to Modified Kuppuswamy Scale: Classes 1, 2, 3 of Modified Kuppuswamy Scale were included in the upper socio economic class. Classes 4 and 5 were included in the lower socio economic class.

Table 2: Risk factors for PCOS.

\begin{tabular}{|c|c|c|c|c|c|}
\hline Characteristic & $\begin{array}{l}\text { Total } \\
\mathbf{n}=\mathbf{1 0 0}\end{array}$ & $\begin{array}{l}\text { Healthy }(\%) \\
\mathrm{n}=79\end{array}$ & $\begin{array}{l}\operatorname{PCOS}(\%) \\
\mathrm{n}=21\end{array}$ & $\begin{array}{l}\text { Odds ratio ( } 95 \% \\
\text { confidence interval) }\end{array}$ & $\begin{array}{l}\text { Chi square test/ } \\
\text { P value }\end{array}$ \\
\hline \multicolumn{6}{|l|}{ Physical activity } \\
\hline Present & 52 & $45(86.54 \%)$ & $7(13.46 \%)$ & \multirow{2}{*}{$2.62(0.99-7.63)$} & 3.71 \\
\hline Absent & 48 & $34(70.83 \%)$ & $14(29.17 \%)$ & & $\mathrm{p}=0.05$ \\
\hline \multicolumn{6}{|c|}{ Past menstrual cycle* } \\
\hline Regular & 66 & $64(96.97 \%)$ & $2(3.03 \%)$ & \multirow{2}{*}{$38.53(9.16-268)$} & 37.78 \\
\hline Irregular & 34 & $15(44.12 \%)$ & $19(55.88 \%)$ & & $\mathrm{p}<0.0001$ \\
\hline \multicolumn{6}{|l|}{ Diet } \\
\hline Vegan & 20 & $14(70 \%)$ & $6(30 \%)$ & \multirow{2}{*}{$0.54(0.17-1.75)$} & 1.22 \\
\hline Mixed & 80 & $65(81.25 \%)$ & $15(18.75 \%)$ & & $\mathrm{p}=0.27$ \\
\hline \multicolumn{6}{|l|}{ BMI** } \\
\hline Normal & 63 & $58(92.06 \%)$ & $5(7.94 \%)$ & \multirow{2}{*}{$8.61(2.89-29.24)$} & 17.52 \\
\hline Overweight/Obese & 37 & $21(56.76 \%)$ & $16(43.24 \%)$ & & $\mathrm{P}<0.0001$ \\
\hline \multicolumn{6}{|l|}{ Waist hip ratio } \\
\hline$\leq 0.85$ & 58 & $51(87.93 \%)$ & $7(12.07 \%)$ & \multirow{2}{*}{$3.59(1.30-10.54)$} & 6.64 \\
\hline$\geq 0.86$ & 42 & $28(66.67 \%)$ & $14(33.33 \%)$ & & $\mathrm{p}=0.005$ \\
\hline
\end{tabular}

p value $<0.05$ is considered significant; *The menstrual cycle was classified as irregular if: -The cycles were more than 35 days apart -Bleeding occurred more frequently than 21 days or lasted longer than 8 days -Late, early or missed cycles; **Normal BMI (18.5-

24.9). BMI more than 25 were considered overweight and a BMI more than 30 as obese.

From the study it was found that the incidence of Poly Cystic Ovarian Syndrome is high in the age group less than 24 years $(26.22 \%)$. Women belonging to the lower socio economic class (includes Modified Kuppuswamy Class 4,5$)$ had a significant 0.31 times lower risk $(95 \%$ CI- 0.11-0.85, $\mathrm{p}=0.01$ ) of developing PCOS as compared to those belonging to higher socio economic class (involves class 1, 2, 3 of Modified Kuppuswamy Scale) (Table 1).
When the risk factors for PCOS were assessed, it was seen that women with lack of physical activity (i.e. exercise less than 3 days a week) were at a 2.62 times higher risk (95\% CI- 0.99-7.63, p=0.05) of developing PCOS as compared to those who regularly exercised. Physical activity if done for more than 3 days a week was considered as present. The relationship of regularity of menstrual cycle had a significant association with development of PCOS. Women having irregular menstrual cycle are at a risk of developing PCOS which is 38.53 times higher $(95 \%$ CI- 9.16-268, $\mathrm{p}<0.0001)$ than 
the ones with a regular/normal menstrual cycle. Women with a BMI more than 25 were considered overweight and a BMI more than 30 as obese. These women were at an 8.61 times higher risk (95\% CI- 2.89-29.24, $\mathrm{p}<0.0001$ ) of developing PCOS as compared to those with a normal BMI (18.5-24.9). Also the Waist-Hip Ratio was calculated as a measure of abdominal obesity and it was found that women with Waist-hip ratio above 0.86 have a 3.59 times higher risk (95\%CI- 1.30-10.54, p=0.005) of developing PCOS against the women whose Waist-hip ratio is within 0.85 (Table 2 ).

Table 3: Awareness of PCOS and its complications among the participants.

\begin{tabular}{|c|c|c|c|c|c|}
\hline Characteristic & $\begin{array}{l}\text { Total } \\
\mathrm{n}=\mathbf{1 0 0}\end{array}$ & $\begin{array}{l}\text { Healthy } \\
n=79(\%)\end{array}$ & $\begin{array}{l}\text { PCOS } \\
\mathrm{n}=21(\%)\end{array}$ & $\begin{array}{l}\text { Odds ratio ( } 95 \% \\
\text { confidence interval) }\end{array}$ & $\begin{array}{l}\text { Chi square test/ } \\
\text { p Value }\end{array}$ \\
\hline \multicolumn{6}{|c|}{ Awareness of PCOS } \\
\hline Yes & 32 & $22(27.84 \%)$ & $10(47.62 \%)$ & \multirow{2}{*}{$0.42(0.16-1.17)$} & 2.98 \\
\hline No & 68 & $57(72.16 \%)$ & $11(52.38 \%)$ & & $\mathrm{p}=0.042$ \\
\hline \multicolumn{6}{|c|}{ Awareness of complications } \\
\hline Yes & 16 & $12(15.19 \%)$ & $4(19.05 \%)$ & \multirow{2}{*}{$0.76(0.22-3.04)$} & 0.18 \\
\hline No & 84 & $67(84.81 \%)$ & $17(80.95 \%)$ & & $\mathrm{p}=0.33$ \\
\hline
\end{tabular}

$\mathrm{p}$ value $<0.05$ is considered significant

Table 4: Presence of dysmenorrhoea and stress.

\begin{tabular}{|c|c|c|c|c|c|}
\hline Characteristic & $\begin{array}{l}\text { Total } \\
n=100\end{array}$ & $\begin{array}{l}\text { Healthy }(100 \%) \\
n=79\end{array}$ & $\begin{array}{l}\operatorname{PCOS}(100 \%) \\
n=21\end{array}$ & $\begin{array}{l}\text { Odds ratio ( } 95 \% \\
\text { confidence interval) }\end{array}$ & $\begin{array}{l}\text { Chi square test/ } \\
\text { P value }\end{array}$ \\
\hline \multicolumn{6}{|l|}{ Dysmenorrhoea } \\
\hline Yes & 26 & $16(20.25 \%)$ & $10(47.61 \%)$ & \multirow{2}{*}{$0.28(0.101-0.79)$} & 6.45 \\
\hline No & 74 & $63(79.75 \%)$ & $11(52.39 \%)$ & & $\mathrm{p}=0.005$ \\
\hline \multicolumn{6}{|l|}{ Stress } \\
\hline Yes & 20 & $20(15.18 \%)$ & $8(38.09 \%)$ & \multirow{2}{*}{$0.55(0.19-1.59)$} & 1.34 \\
\hline No & 80 & $59(84.82 \%)$ & $13(61.91 \%)$ & & $\mathrm{p}=0.12$ \\
\hline
\end{tabular}

$\mathrm{p}$ value $<0.05$ is considered significant

When these 100 participants were asked about their knowledge of PCOS it was seen that amongst the total sample only 32 women had awareness of PCOS, which was through their doctors, relatives, or books. Out of the total sample, the percentage of women who were suffering from PCOS and were aware about what it is was only $47.62 \%$. When asked about how many of them knew of the complications a woman suffering from PCOS can have in her life time, we found a sad figure of $19.05 \%$ (Table 3).

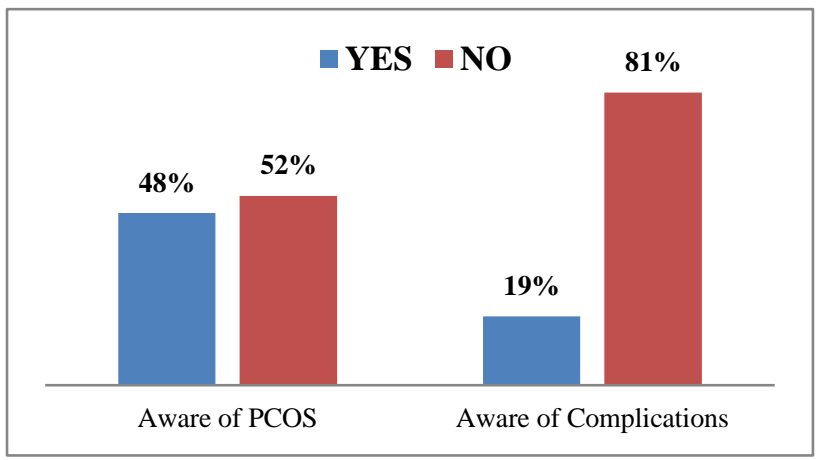

Figure 2: Awareness of PCOS and its complications among PCOS sufferers.
Amongst these the women who themselves had PCOS and were unaware of its complications were a huge $80.95 \%$ (Figure 2).

The percentage of healthy women suffering from dysmenorrhoea was $20.25 \%$, while in women suffering from PCOS it was as high as $47.61 \%$. The value was significant (95\% CI- 0.10-0.79, $\mathrm{p}=0.005)$. It was also found that the percentage of stress sufferers among healthy women was $15.18 \%$ whereas amongst PCOS patients it was $38.09 \%$ (Table 4).

\section{DISCUSSION}

Poly Cystic Ovarian Syndrome (PCOS) is an emerging health issue among the females because of the changes in lifestyle, the increasing stress levels accompanied with lack of physical activity and gross changes in the pattern of menstrual cycles. As of now, there is no permanent cure to the problem, therefore the most effective and important solution would be to prevent its development and to make an early diagnosis of the condition so that the serious long term complications may be avoided. This study thus aimed to find the incidence of PCOS among women attending the Gynecology OPD of a tertiary 
health care hospital in Western Maharashtra and the associated risk factors. One of the secondary objectives was to check for the awareness regarding the condition and its complications among the healthy women and those affected by PCOS.

In the study it was found that the incidence of PCOS was $21 \%$. So far there is no study which clearly states the prevalence/incidence of PCOS in India. Various studies have suggested the prevalence to be between $10 \%$ $36 \%$ which are in accordance with the study. ${ }^{3}$ Also studies have shown the prevalence of PCOS to be higher in urban areas as compared to rural areas which supports the higher incidence in the setting as it is an urban area. ${ }^{5}$

It was seen that the maximum number of cases were reported in the age group $\leq 24$ ( $76 \%$ of the total PCOD cases). Similar results were found in a prospective study conducted by Renatt C Francis in Palakkad where it was observed that the maximum number of PCOS patients of age belongs to $21-25$ years $(34.2 \%) .6$ So the estimated prevalent age group is $21-25$ years. $^{6}$ A study in Bhopal also reported comparable findings. ${ }^{7}$

Women belonging to upper socio economic class had significantly more cases of PCOS compared to those of the lower class. This fact may be attributed to the difference of life style, eating habits etc. A hospital based study conducted at Jaipur, from April 2013 to March 2014 also reported similar findings with the prevalence of PCOD being $64 \%$ in the middle and upper classes. ${ }^{8}$

This study showed that $27 \%$ women with lack of physical activity developed PCOS which was more as compared to those who regularly exercised. Therefore the significance of lack of physical activity in development of PCOS is found. Other studies have also given findings which are similar to our study the. ${ }^{5,9}$ This may be due to the positive effect regular exercise has on our health and may also be related to the control of weight gain.

From the study it was seen that $56 \%$ women with irregular menstrual cycle reported to be suffering from PCOS. This percentage was significantly higher as compared to the women with regular menstrual cycle. Immaturity of hypothalamic-pituitary-ovarian axis in girls causing anovulation due to suboptimal FSH and LH production causes irregular menses. ${ }^{6}$ Anovulation persists and continues as chronic anovulation. The resulting hyperestrogenism, leads to hyperandrogenism, manifesting clinically as irregular menses. ${ }^{6}$ Similar results as our study were shown by studies conducted at various places. ${ }^{1,6,10}$

When the BMI of the participants was calculated, it was seen that $43 \%$ of the overweight women suffered from PCOS. A retrospective study in Tamil Nadu also showed that $40 \%$ of the obese women were suffering from PCOS. ${ }^{5}$ Another cross-sectional study conducted in Dehradun concluded that obesity minimally increases risk of PCOS. ${ }^{1}$ The link between obesity and PCOS is further strengthened by the facts that a lifestyle change and control of weight will reduce the symptoms of PCOS and help reverse the hormonal imbalance. ${ }^{1}$

When the waist hip ratios of the women were calculated it was found that a waist hip ratio above 0.85 posed a 3.59 times higher risk of developing PCOS. A similar study also showed significant association between the waist circumference and development of PCOS $(\mathrm{p}<0.009) .{ }^{11}$ Studies have also proved that increased abdominal fat is significantly associated with development of insulin resistance which is one of the major complications of PCOS. ${ }^{11}$ Another study done in Bhopal showed a strong association between Waist hip ratio and development of PCOS $(\mathrm{p}<0.0001){ }^{7}$ Thus by controlling this parameter we may be able to control the development of insulin resistance and subsequently development of type 2 diabetes in these women.

Being aware about a disease and its complications encourages people to seek early timely treatment and also helps in the prevention of further complications. Knowing the level of awareness about a particular disease is important aspect of primary health care. In this study it was found that the total percentage of women aware about PCOS was only $32 \%$, out of which only $16 \%$ were aware about the further complications. This shows the need of creating awareness amongst women and girls regarding PCOS so that they can identify the symptoms as early as possible. It will also help protect them from complications such as infertility at a later stage. Other study showed lack of awareness among $78 \%$ women in Bhopal. ${ }^{7}$ In another study done among working women in Mumbai awareness about PCOS was seen to be $60 \% .^{12}$ This difference may be due to the fact that the proportion of educated women in urban areas is more than that at rural areas.

The unaware women were then educated about PCOS, it's consequences. They were even told why this syndrome develops and its associated risk factors. The women were also made aware of the lifestyle modifications which are necessary to prevent its development.

We also found that the level of stress was high among PCOS patients $(38.09 \%)$. Similarly in women suffering from PCOS presence of dysmenorrhoea was as high as $47.61 \%$. This point towards the additional physical and psychological pain the women with PCOS go through. ${ }^{12}$ One more randomized control study conducted in Mumbai revealed significant data on the psychological aspect this syndrome can have on women. ${ }^{13}$

\section{CONCLUSION}

The socio-economic class, BMI, Waist-hip ratio and the past menstrual cycle of a woman were found to strongly influence the development of PCOS in them. Lack of 
physical activity was also a significant risk factor in the development of PCOS. This indicates the association of this syndrome with the changing sedentary lifestyle that has been adopted by the people these days.

Also the awareness about PCOS among PCOS sufferers was only $47.62 \%$, and the awareness of its complications was further low $(19.05 \%)$ indicating a need to educate the women regarding this syndrome and its associated complications. The need for information about the changes which are needed in their lifestyle so that the incidence of this syndrome can be reduced is very obvious from the results. Therefore the women who participated in this study were made aware about this syndrome, its complications and how to prevent it.

\section{ACKNOWLEDGMENTS}

Authors would like to thank Mr. Suresh Namdev Shinde and Mrs. Pushparani Shinde for their valuable suggestions and support, time and again. Authors also thank ICMR for encouraging research work among medical students.

Funding: No funding sources Conflict of interest: None declared

Ethical approval: The study was approved by the Institutional Ethics Committee

\section{REFERENCES}

1. Choudhary A, Jain S, Chaudhari P. Prevalence and symptomatology of polycystic ovarian syndrome in Indian women: is there a rising incidence? Int J Repro Contracept Obstet Gynecol. 2017;6(11):497175.

2. Kabel AM, Alghubayshi AY, Moharm FM. The impact of Polycystic Ovarian Syndrome, a potential risk factor to Endometrial Cancer, on the quality of sleep. J Cancer Res Treat. 2016;4(6):96-8.

3. Joshi B, Mukherjee S, Patil A, Purandare A, Chauhan S, Vaidya R. A cross-sectional study of polycystic ovarian syndrome among adolescent and young girls in Mumbai, India. Indian J Endocrinol Metabol. 2014;18:317-24.

4. Gottschau M, Kjaer SK, Jensen A, Munk C, Mellemkjaer L. Risk of cancer among women with polycystic ovary syndrome: a Danish cohort study. Gynecol Oncol. 2015;136(1):99-103.
5. Bharathi RV, Swetha S, Neerajaa J, VarshaMadhavica J, Janani DM, Rkha SN, et al. An epidemiological survey: Effect of predisposing factors for PCOS in Indian urban and rural population. Middle East Fertility Society J. 2017;22:313-6.

6. Francis RC, Sajeeth CI, Mini NM. Prevalence, risk factors and treatment strategies of polycystic ovary syndrome at various hospitals, Palakkad: A prospective study. Int $\mathbf{J}$ Innov Res Med Sci. 2017;2(6):784-8.

7. Gupta M, Singh D, Toppo M, Priya A, Sethia S, Gupta P. A cross sectional study of polycystic ovarian syndrome among young women in Bhopal, Central India. Int $\mathbf{J}$ Comm Med Pub Health. 2018;5(1):95-100.

8. Sowmya D, Anitha S. Clinical study of polycystic ovarian syndrome (PCOS) in tertiary care centre. Int J Reproduct Contracept Obstet Gynecol. 2017;6:3247-51.

9. Begum GS, Shariff A, Ayman G, Mohammad B, Housam R, Khaled N. Assessment of risk factors for development of polycystic ovarian syndrome. Int $\mathbf{J}$ Contemp Med Res. 2017;4(1):164-7.

10. Mitra P, Guria S, Ghosh S, Chakraborti S, Chakraborty A, Das S, et al. A preliminary study of clinical manifestations of polycystic ovary syndrome (PCOS) in Kolkata. Int J Res Develop Pharma Life Sci. 2016;5(2):2074-9.

11. Kalra P, Bansal B, Nag P, Singh JK, Gupta RK, Kumar S, et al. Abdominal fat distribution and insulin resistance in Indian Women with Polycycstic Ovarian Syndrome. Fert Ster. 2009;91(4):1437-40.

12. Kumari M, Walavalkar R, Shaikh M, Harshal A, Rane S, Nandini D. Prevalence of polycystic ovary syndrome among women in Mumbai and association of its symptoms with work hours. Int J Innov Res Sci Eng Tech. 2017;6(7):13609-16.

13. Bindu BR. Increasing incidence of PCOS in adolescence and its relation with mental stress. Res Recent Sci. 2014;3:227-30.

Cite this article as: Shinde KS, Patil SS. Incidence and risk factors of polycystic ovary syndrome among women in reproductive age group attending a tertiary health care hospital in Western Maharashtra. Int J Reprod Contracept Obstet Gynecol 2019;8:2804-9. 